ally have not been successful. The changes described by $\mathrm{H}$. Pinkus and A. H. Mehregan ${ }^{12}$ are characteristic of parakeratosis, whether in psoriasis or other conditions.

Unna and more particularly Sabouraud favoured the infective origin of seborrhoeic dermatitis. Much of their work has been invalidated by improved microbiological techniques, but investigations by G. B. Dowling ${ }^{13}$ in 1939 still favoured the infective theory. The increased interest recently taken in the lipophilic yeasts is rapidly adding to our knowledge of the biology of these neglected members of the skin flora. In the light of this new knowledge the microbiology of carefully defined cases of seborrhoeic dermatitis should be investigated again and correlated with possible changes in the composition of the surface lipids. Seborrhoeic dermatitis has been observed confined to the affected side of syringomyelia, ${ }^{14}$ to the affected dermatome in a trigeminal nerve lesion, ${ }^{15}$ and to the paralysed side in hemiplegics. Such patients provide their own controls for a combined investigation by biochemists and microbiologists. Meanwhile our patients and the advance of dermatology are best served by a critical, almost reluctant, use of a diagnostic label which is easily abused.

1 Parrish, J. A., and Arndt, K. A., British Fournal of Dermatology, 1972, 87, 241.

2 Radcliffe-Crocker, H., Diseases of the Skin, 3rd edn., 2, 1052. London,

Lewis, 1903.
Jacobs, J. C., and Miller, M. E., Pediatrics, 1972, 49, 225

Leiner, C., Archiv fur Dermatologie und Syphilogie (Wien), 1908, 89, 163 Fox, T. C., Pityriasis, in A System of Medicine, ed. C. Allbutt and H. D Rolleston, 9, p. 202. London, Macmillan, 1911.

6 Duperrat, B., Precis de Dermatologie. Paris, Masson, 1959.

7 Booken, G., Hautarzt, 1968, 19, 115.

Grasset, N., and Brun, R., Dermatologica, 1959, 119, 232

9 Pochi, P. E., Strauss, J. S., and Mescon, H., Fournal of Investigative Dermatology, 1962, 38, 45 .

${ }^{10}$ Burton, J. L., Cartlidge, M., and Shuster, S., British Fournal of Derma-

tology, in press.
11 Parish, L. C., New England fournal of Medicine, 1970, 283, 879.

12 Pinkus, H., and Mehregan, A. H., fournal of Investigative Dermatology, 1966, 46, 109.

13 Dowling, G. B., British fournal of Dermatology, 1939, 51, 1.

14 Tronnier, H., Zeitschrift fur Haut und Geschlechtskrankheiten, 1964, 37, 207.

15 Bettley, F. R., and Marten, R. H., Archives of Dermatology, 1956, 73, 110.

\section{Problems of Iron-deficiency Anaemia in Infancy}

Iron-deficiency in infants in association with gastrointestinal blood loss, hypoalbuminaemia, hypocupraemia, ${ }^{1-3}$ and microscopic changes in the duodenal villi4-6 has been reported. These infants had been fed on whole cow's milk (pasteurized and homogenized as supplied by most dairies) and often in excessive amounts. The hypoalbuminaemia and hypocupraemia suggested the existence of a protein-losing enteropathy. It has been proposed that fresh cow's milk may produce occult loss of blood from the gastrointestinal tract, which in turn leads to iron-deficiency anaemia. ${ }^{1}$ An alternative proposal is that iron deficiency alone alters intestinal function and thereby causes an absorptive and exudative enteropathy. ${ }^{4}$

To define the role of milk and of iron in the pathogenesis of the altered instestinal function in infants with iron-deficiency anaemia C. W. Woodruff and J. L. Clark ${ }^{7}$ measured the separate effect of iron treatment and of changing the intake of milk. Their 12 infants, from 7 to 17 months old, were of normal birth weight and had been fed fresh cow's milk for 3 to 12 months before the study, the daily intake being be- tween $700 \mathrm{ml}$ and $1,900 \mathrm{ml}$. Most of the infants were anaemic, with haemoglobin concentrations well below $9 \mathrm{~g} /$ $100 \mathrm{ml}$; the red cells were microcytic and hypochromic; the serum iron was low; and the serum iron-binding capacity was raised. None had renal or liver disease. To find the amount of protein lost through the bowel the turnover rate of serum albumin labelled with iodine-131 was measured. This method has shown changes in protein loss in patients with milk allergy and intestinal lymphangiectasia following dietary changes known to produce clinical improvement. The use of a whole-body counter allowed the use of very low doses of radioactivity $(0 \cdot 12$ microcuries), eliminated the need for quantitative collections of stools, and detected changes in intestinal function within 24-28 hours of beginning treatment. Six normal infants aged $12-15$ months served as controls.

Seven of the 12 infants with iron-deficiency anaemia had an abnormally rapid albumin turnover rate. This was not affected by $100 \mathrm{mg}$ iron dextran injected intramuscularly, though there was evidence of a haematological response. Substituting reconstituted evaporated milk for fresh cow's milk led to a striking change in albumin turnover rate, which became normal in two infants and slower in another two. In two infants in whom the albumin turnover rate did not become normal when given evaporated milk the feeding of a soybean formula milk was followed by a normal turnover rate within two days. The serum copper concentration also increased, but the serum albumin concentration remained unchanged.

Of the 12 infants with iron-deficiency anaemia studied by Woodruff and Clark $^{7}$ five had normal albumin turnover rates, and it is therefore clear that iron-deficiency anaemia in itself is not necessarily associated with a protein-losing enteropathy. Furthermore the failure to find a rise in serum albumin concentration in those infants who were changed from fresh milk to either evaporated milk or a soybean formula and in whom the albumin turnover rate became normal appears puzzling. To clarify this problem albumin synthesis rates and distribution spaces will need to be measured.

The change in albumin turnover rate within 48 hours of changing the milk feed is also the time necessary for complete replacement of the epithelial cells of the intestinal villi, which suggests that the observed changes in albumin turnover may depend on regeneration of these cells. The finding of antibodies to fresh cow's milk in both serum and faeces of most of the infants with protein-losing enteropathy suggests that a factor in fresh milk, possibly a protein, may be involved. Although diarrhoea was not part of the clinical picture, there is a resemblance to milk-induced colitis. ${ }^{8}$

From these observations it seems likely that the development of iron deficiency in some of the infants is consequent on an alteration in the intestinal mucosa induced by ingestion of excessive amounts of fresh cow's milk. However, it is clear that not all infants with iron-deficiency anaemia show a protein-losing enteropathy as judged by an increased albumin turnover rate, and this suggests that there may be an individual susceptibility to the intestinal effects of fresh cow's milk. Most of the anaemic infants in Woodruff and Clark's study had occult blood in their faeces, and it is likely that the iron-deficiency was due at least in part to chronic gastrointestinal blood loss, presumably a result of mucosal damage induced by fresh cow's milk.

To see whether there was individual susceptibility to fresh cow's milk a prospective study ${ }^{9}$ was carried out on 
normal infants who were fed from the age of 2 months until 12 months old on either fresh cow's milk or a prepared formula which was introduced into the diet. At the end of the study the infants fed fresh cow's milk had a marginally lower haemoglobin level and mean cell volume; their serum iron concentration was lower at 6 months of age but not different from the normal group at 12 months. Occult blood tests were positive in most of the infants in both groups. Milk antibodies were found in four of the infants fed fresh milk and in one fed the formula when tested at 12 months of age.

This study did not show a striking difference in the iron status of the normal babies fed fresh milk compared with those receiving formula, and the relevance of these studies to those carried out on infants with established iron-deficiency anaemia is conjectural. The possibility of individual susceptiblity to fresh cow's milk in those with iron-deficiency anaemia cannot be excluded. It remains to be seen how common this condition is, and the exact way in which the enteropathy and the iron-deficiency develop and their interrelationship require further elucidation.

1 Wilson, J. F., Heiner, D. C., and Lahey, M. E., fournal of the American Medical Association, 1964, 189, 568.

2 Hoag, M. S., Wallerstein, R. O., and Pollycove, M., Pediatrics, 1961, 27, 199 .

3 Schubert, W. K., and Lahey, M. E., Pediatrics, 1959, 24, 710.

4 Naiman, J. L., Oski, F. A., Diamond, L. K., Vawter, G. F., and Schwachman, H., Pediatrics, 1964, 33, 83.

5 Visakorpi, J. K., and Kuitunen, P., Annales Paediatriae Fenniae, 1966, 12

- Guha, D. K., Walia, B. N. S., Tandon, B. N., Deo, M. G., and Ghai, O. P., Archives of Disease in Childhood, $1968,43,239$.

7 Woodruff, C. W., and Clark, J. L., American fournal of Diseases of Children, $1972,124,18$

${ }^{8}$ Katz, J., Spiro, H. M., and Herskovic, T., New England fournal of Medicine, 1968, 278, 1191 .

- Woodruff, C. W., Wright, S. W., and Wright, R. P., American fournal of Diseases in Children, 1972, 124, 26.

\section{"Steal" Syndromes and Hypertension}

When an artery becomes obstructed blood may be diverted into its distal segment, where the pressure is lower, via collaterals from a normally perfused arterial territory nearby. Hypoxia-induced vasodilatation may cause further diversion, and if this becomes excessive it may actually lead on to ischaemic symptoms in the donor territory. This mechanism has been called arterial "steal." Blood is stolen from the healthy territory, and the result is to give a false localization of the site of the arterial disease.

The first steal syndrome to be described resulted from reversed flow down the vertebral artery into the subclavian artery beyond a stenosis in its first part. ${ }^{1}$ Symptoms of brainstem ischaemia precipitated by arm exercise were reported. Subclavian steal does not always follow occlusion near the origin of the subclavian artery. It is rare after subclavian-pulmonary artery anastomosis for the palliation of the tetralogy of Fallot, and the anatomy of the circle of Willis in individual patients probably determines the outcome.

The concept of the steal syndrome proved to be attractive, and aorto-iliac, ${ }^{2}$ mesenteric, ${ }^{34}$ spinal,, $5^{5}$ and coronary 6 steals have since been described.

The concept of coronary steal is interesting but difficult to prove. D. B. Effler and associates at the Cleveland
Clinic, Ohio, suggested the term "coronary steal" for the situation which arises in the anomalous origin of the left coronary artery from the pulmonary artery. ${ }^{7}$ In this condition blood flows from the normally arising right coronary artery via intercoronary anastomoses into the lower-pressure left coronary artery and thus retrograde into the pulmonary artery. Blood is "stolen" from the territory of the normal coronary artery. Ligation of the anomalous coronary artery at its origin from the pulmonary artery can alleviate the symptoms of myocardial ischaemia. More recently it has been postulated that a similar diversion of flow may occur in acquired occlusive coronary artery disease. ${ }^{8}$ We are accustomed at coronary angiography to seeing retrograde filling of the distal segment of a coronary artery beyond an obstruction. Thus contrast injected into the left coronary artery may fill the distal part of an obstructed right coronary artery. Certain coronary vasodilator dugs have been known to precipitate angina. By causing vasodilatation in the healthy parts of the coronary tree it is possible that they may reduce collateral flow and steal blood away from an ischaemic territory.

Now R. J. Alfidi and colleagues, of the Cleveland Clinic, have added three further cases of renal-splanchnic steal to the original example reported in 1967.910 In Alfidi and colleagues' patients renal ischaemia, with consequent hypertension, resulted from diversion of blood away from the right kidney into branches of the coeliac axis distal to obstruction of its main stem. The four patients, all women, had large collateral arteries running upwards from the right renal artery into a radical of the coeliac axis. All four patients had presented with high blood pressure. Two of them had a bruit in the abdomen. Renal artery stenosis was suspected but none found. Instead they all showed arterial flow away from the right kidney to enter an enlarged inferior adrenal artery and thence via a superior renal artery to a branch of the coeliac artery. The diagnosis of hypertension due to this mechanism depends on failure to find stenosis of a renal artery in a patient in whom this has been suspected, recognition of the enlarged vessels leaving the kidney, and angiographic demonstration of a stenosis of the coeliac axis.

The authors warn against surgical ligation of the steal vessels, because interruption of the collateral supply to the splanchnic bed could precipitate mesenteric angina or even gangrene of the small intestine. This actually occurred after spontaneous thrombosis of the steal vessel in one of their patients. They recommend that surgical efforts should be directed towards re-establishment of a normal splanchnic blood supply, as this would eliminate the renal steal and correct ischaemia in both the donor and the recipient territory. As in other types of renal hypertension due to renal ischaemia, the high blood pressure may persist even after removal of its cause.

1 Reivich, M., Holling, H. E., Roberts, B., and Toole, J. F., New England fournal of Medicine, 1961, 265, 878

Kountz, S. L., Laub, D. R., and Connolly, J. E., Archives of Surgery, 1966, 92, 490.

Reuter, S. R., and Olin, T., Radiology, 1965, 85, 617.

Bucheler, E., Düx, A., and Rohr. H., Fortschritte auf dem Gebiete der Röntgenstrahlen und der Nuklearmedizin, 1967, 106, 313.

5 Doppman, J. L., Di Chiro, G., and Ommaya, A. K.. Selective Arteriography of the Spinal Cord, p. 67. St. Louis, Warren H. Green, 1969.

6 Baker, L. D., Snow, J. A., Pomposiello, J. C., Sharma, G.V.R.K., and Messer, J. V., Clinical Resea ch, 1969, 17, 228.

7 Effler, D. B., Sheidon, W. C., Turner, J. J., and Groves, L. K., Surgery, 1967, 61. 41

8 Fam, W. M., and McGregor, M., Circulation Research, 1964, 15. 355 9 Alfidi, R. J., Filson. E. J., and Frohlich, E. D., Cleveland Clinical Quarterly, 1967, 34, 43.

10 Alfidi, R. J., et al., Radiology, 1972, 102, 545. 